\title{
Coastal communities, participatory research, and far-field effects of aquaculture
}

\author{
Jonathan Grant \\ Department of Oceanography, Dalhousie University, Halifax, Nova Scotia B3H 4J1, Canada
}

\begin{abstract}
Marine aquaculture is controversial in coastal communities for a variety of reasons, including environmental and aesthetic concerns. Shellfish and especially finfish farming have the potential to cause eutrophication effects on the bottom, and reduce oxygen levels in the water column. Active participation of citizens in data gathering before and after development provides a mechanism of engagement in the science used for development decisions. I examine how participatory science can solve 2 problems: insight into far-field impacts of aquaculture, and entrainment of coastal stakeholders into the decision process. Working with a community group, I suggest sediment profile imaging as a method that could be employed by coastal residents, including participation in image analysis of the apparent redox potential discontinuity, a validated visual indicator of coastal benthic conditions. The implementation of rigorous science, with applicability to ecosystem health and capacity for public participation is key in ecosystem-based management.
\end{abstract}

KEY WORDS: Coastal commities - Aquaculture - Sediment profile images - Benthic impacts · Coastal zone management

Resale or republication not permitted without written consent of the publisher

\section{INTRODUCTION}

Marine aquaculture is controversial in coastal communities for a variety of reasons, including environmental and aesthetic concerns. Shellfish and especially finfish farming has the potential to cause eutrophication effects on the bottom, and reduce oxygen levels in the water column. These impacts may be obvious as sulfur odors due to anaerobic metabolism, nuisance algae due to nutrification, and aggregates of decomposing food and feces in the swash zone (Hargrave 2005). Because coastal areas may rely on capture fisheries, there is the perception that ecosystem health is compromised and target stocks such as lobster are jeopardized. For seasonal occupants with recreational aims, the above effects as well as the appearance of buoys or cages constitute a degradation of the coastal environment. For many aquaculture operations, there is a measurable impact beneath cages or longlines (Wildish et al. 2003), but it has been difficult to document the far-field effects. Government regulators must therefore counter not only the realities of environmen- tal impacts but the perception of impacts, in the absence of a scientific understanding of the far-field.

Like many industries, aquaculture has made improvements with respect to sustainability, and companies recognize that consumers attempt environmentally responsible choices, especially with natural products. In earlier stages of seafarming, husbandry practices were less developed, partly accounting for the poor reputation that lingers today. Conflicts involving aquaculture development and coastal communities are in part due to this legacy. In addition, the science of aquaculture management has progressed with regard to monitoring and modeling (Filgueira \& Grant 2009), so overall, some of the risk to coastal environments is reduced.

Nonetheless, there have been many conflicts between aquaculture development and coastal communities (Hovik \& Stokke 2007). Decisions regarding whether proposed marine farms should proceed are often imposed on coastal regions with little consultation, and no participation of residents in planning, data collection, or subsequent monitoring. Measurements of 
environmental conditions in the field are at the core of these conflicts as well as their resolution. Active participation of citizens in data gathering before and after development provides a mechanism of engagement in the science used for development decisions.

Participatory research or citizen science is a mode of involving coastal residents in research programs, and subsequently in policy decisions. Via this mechanism, citizens have a stake in the datasets used for planning and decision making. There are numerous stakeholder, academic or government groups leading these research efforts, and their input to public policy is well documented (e.g. Kawabe 2004, Bastien-Daigle \& Vanderlinden 2008).

With respect to aquaculture, most of the general research emphasis is on near-field or local effects. However, coastal residents are often concerned about larger scale impacts, especially as they relate to livelihoods such as local fisheries or tourism. Beaches fouled with nuisance algae are a vivid example of this distant effect (Heaslip 2008). For this reason, regulatory bodies that traditionally focus on near-field impacts (e.g. cages vs. control sites) are mismatched in their perspective with that of coastal communities who inherently focus on a larger spatial scale. For example, in Canada, some site monitoring programs require samples only within the leases and a single reference site (Wildish et al. 2001, Heaslip 2008). This is not because of lack of diligence by regulators, but rather due to the state of science which dwells on localized spatial scales.

Prior to science-based decisions, there is a set of objectives one might propose for coastal residents facing development scenarios:

(1) An ability to participate in scientific data collection as well as interpretation of the results.

(2) Confidence that validated environmental information is available to them and that adaptive management changes can be made on this basis.

(3) An ability to interact in the management process, including ecosystem-based management.

These expectations may exceed the capacity of regulators to provide information; e.g. the tenets of ecosystem-based management in this context are still developing. For this reason, contributions to approaches to far-field impacts, even if limited (see below), are still valuable. Participatory research is only one example of the type of input that could ease the process of aquaculture implementation in coastal communities. Other forms of community learning and consultation beyond the science are also undoubtedly important (Meffe et al. 2002). This has been demonstrated in numerous examples from Atlantic Canada (Bastien-Daigle \& Vanderlinden 2008).

In this perspectives paper, I examine how participatory science can address 2 problems: insight into far-field impacts of aquaculture, and entrainment of coastal stakeholders into the decision process. Specifically, I will:

(1) Provide an example of the type of measurements that can be utilized by coastal residents.

(2) Define relevance to ecosystem-level effects.

(3) Define the parameters of a participatory research program and the dissemination of results.

The context for this paper arises from my experience working with community groups in coastal Nova Scotia, including an ongoing issue at a location that will not be disclosed here. A salmon farm was located for more than 10 years at the same site, with no fallowing. Another company has taken over this lease and would like to re-stock after fallowing. There is strong opposition in the community due to alleged impacts of the previous farm. The regulators, federal Department of Fisheries and Oceans, and Nova Scotia Department of Fisheries and Aquaculture are caught between industry and community. I suggested establishing some baseline data regarding the benthic health of the bay prior to re-stocking. A research program ensued as described in the section 'Citizen science'. The data analysis is not yet complete, nor are the development plans for the site finalized. However, the emphasis in the present paper is not science results, but the type of science suitable for citizen participation and interpretation, and its implementation in the decision process.

\section{FAR-FIELD EFFECTS OF AQUACULTURE}

One of the most poorly available sources of impact information concerns the far-field, i.e. beyond the farm boundaries. In general, there are several types of farfield impact that are of concern including discharge of materials such as organic wastes, antibiotics and other therapeutics, and their influence on oxygen conditions, local flora, fauna, fisheries, and habitat (seagrass beds, beaches). Escaped fish pose another type of problem that occurs in the far-field when they interact with native congeners (Jonsson 1997).

In order to assess ecosystem-level impacts of aquaculture, it is necessary to obtain measurements at spatial scales greater than those of local culture sites. Moreover, impacts attributable to aquaculture must be couched in terms of other potential influences, natural and otherwise, on the benthic environment as discussed in 'Citizen science'. There are few studies dealing with far-field impacts. There are numerous candidate indicators of far-field conditions including aquaculture wastes (therapeutics, feed pigments and trace metals, sediment organic matter; Sutherland et al. 2007). However, tracking the spread of a given tracer need not have implications for impacts, and is not in 
itself evidence of far-field negative effects. Instead, variables such as benthic biodiversity can be used with a qualitative scale to ascribe indications of benthic health (Borja et al. 2009a). Despite the availability of these measurements, they are rarely applied in a spatially quantitative way that leads to a baywide or other larger scale view of the ecosystem. Instead, point data are compared at a culture site and a reference site or in small concentric areas surrounding a farm (Hargrave 2005, Heaslip 2008).

Typically, effects are assumed to be attenuated at short distances from farms (Carroll et al. 2003). In a review of far-field effects of finfish aquaculture, the evidence for other than local impacts was surprisingly weak (Hargrave 2005). In one of the rare examples of impacts farther afield, cage culture of finfish led to deleterious sedimentation on seagrass meadows, with most effects attenuated within $400 \mathrm{~m}$ of the cage sites (Holmer et al. 2008). Extensive bivalve culture has potential effects on suspended particle size and quality, as suggested by models but not easy to demonstrate in field measurements (Grant et al. 2008). Organic loading from bivalve biodeposition also seems to disperse rapidly in space (Callier et al. 2008). There are however, examples of larger scale invertebrate aquaculture effects, as in the case of shrimp culture, where mangroves have been removed and ecosystem services of the coastal zone compromised, debilitating local wild shrimp fisheries (Whitmarsh \& Palmieri 2008).

\section{CITIZEN SCIENCE}

The prospect of citizen participation in communitybased science is well established, with numerous initiatives arising from institutional and government bodies. For example, stakeholder participation is central to the EU Marine Strategy Directive (Fletcher 2007). Kaufman et al. (2009) outline the steps required for science to be implemented as action. One of their tenets concerns the importance of local capacity in research. In focusing on this point, I have defined several qualifications for a research technique utilized by citizen scientists:

(1) The method must involve readily accessible and affordable equipment.

(2) Sampling and analyses must be reliable when executed by trained participants.

(3) Data should be in a format readily accessed and transferred between parties involved.

(4) Attendant information on location (GPS) is mandatory.

(5) With training, data should be interpretable by participants.
(6) Measurements should be sensitive to environmental change and the measurement should have some indicative ability related to sustainability.

(7) The measurement should have some sensitivity to far-field impacts.

\section{BENTHIC ECOSYSTEM HEALTH}

The benthos has long been considered a candidate for evaluating ecosystem health, partially due to the integrative nature of benthic response, but also due to the relative stability of conditions over medium time scales. Faunal diversity is a common tool in measuring benthic health, but time consuming and expensive to document (Wildish et al. 2001). Among other variables, those related to oxygenation are important, since oxic conditions are one of the most desired if unstated habitat quality variables. Moreover, hypoxia is a common response to various stresses such as eutrophication, and there are indirect indicators of oxic conditions such as redox potential and sulfide concentration.

Among methods that fulfill these criteria, some form of imaging comes to mind, since visual data may be more familiar to coastal residents than graphs or tables. Specifically, sediment profile imaging (SPI) is a reliable technique with a track record at aquaculture sites. The depth of the redox potential discontinuity (RPD) provides an integrated response to eutrophication or other forms of organic loading such as aquaculture waste.

Redox potential is particularly appealing, since it provides a measure of the extent of oxidized conditions, visually apparent at the RPD. The classic works of Pearson \& Rosenberg (1978) and Rhoads et al. (1978) place the RPD in the context of benthic succession following a disturbance through time or space. The color change from tan oxidized surface sediments to black or gray reduced sediments at depth is caused by the presence of mineral sulfides sequestered from sulfate reduction and thus hypoxic/anoxic conditions. SPI is an in situ technique configured to observe this apparent RPD (aRPD) - among other sedimentary and biotic features - from a vertical slice of sediment. Using a commercially available instrument, a wedge of the sediment is photographed in profile view by means of a mirror within the core (Rhoads \& Germano 1982). This approach has been used by a number of workers to survey impacts of eutrophication, aquaculture, contaminants, etc. (Valente et al. 1992, Diaz \& Trefry 2006, Rosenberg et al. 2009). Recent studies have verified the relationship between sediment/water oxygen content, biodiversity, and the aRPD (e.g. Cicchetti et al. 2006, Diaz \& Trefry 2006), demonstrating its value as a survey tool. In shallow coastal waters, the sediment communities could be argued to be an indicator of local ecosystem health, and not just benthic condition. 
Nilsson \& Rosenberg (1997) defined a benthic habitat quality index (BHQ) to incorporate SPI measures into a single value. I maintain that aspects of SPI are an example of an environmental assessment approach that could be used for citizen-based science for the following reasons:

(1) The measurement has a demonstrable response to oxygen stress and other forms of disturbance.

(2) Data collection is rapid and multiple stations may be surveyed in a day.

(3) The data are rapid to analyze, with a shallow learning curve.

(4) Results may be collated by email.

(5) Logistics and equipment can be utilized in a format that is neither complex nor expensive.

Commercial SPI devices such as REMOTS (www. oceanimagingsystems.com) are prohibitively expensive for community use unless purchased by government and donated for sharing among multiple user groups. However, there is a diver-operated hand core that provides a cost-effective approach to SPI. Wildish et al. (2003) modified an earlier design to produce a Hargrave wedge core, operated by divers, and photographed on the vessel (Fig. 1). Callier et al. (2008) used this corer to examine impacts of mussel culture in the Magdalen Islands, Quebec, Canada. I describe aspects of this approach as a coastal assessment tool accessible to local residents. I emphasize that it is not the only approach to participatory marine science, but has many desirable qualities for a candidate technique.

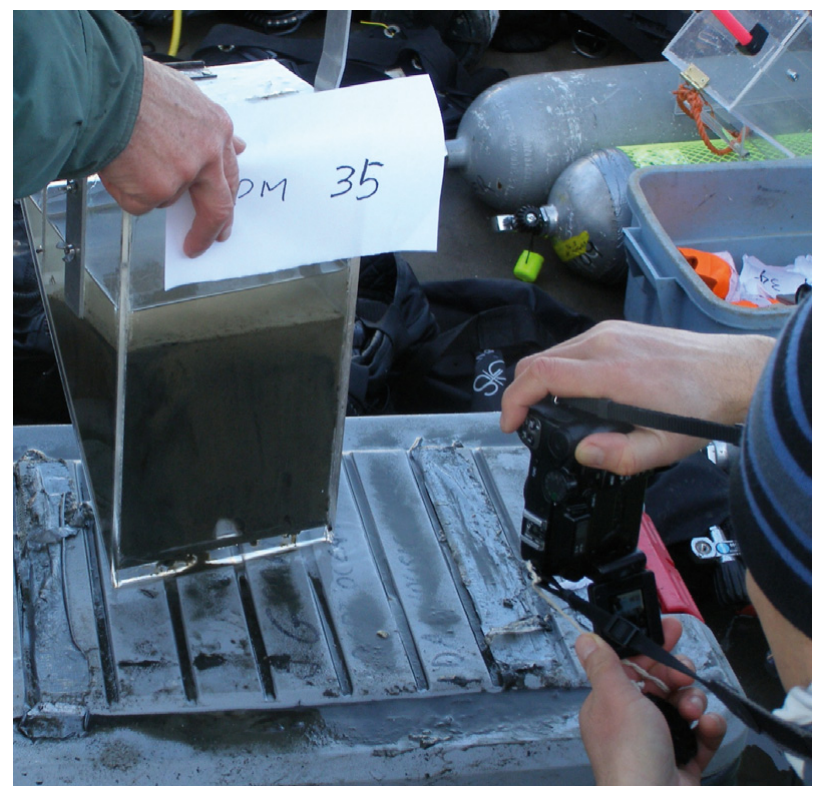

Fig. 1. Diver-sampled Hargrave wedge core being photographed on vessel deck. Lighter region in the uppermost part of the core is overlying water. Core is $17.5 \times 15 \times 35 \mathrm{~cm}$
Various descriptions of this methodology exist (Rosenberg et al. 2001), but most lack detail of the analysis, especially the image analysis. Software is available specifically for analyzing SPI images (www.vsg.dcu.ie/code.html), but is dependent on higher resolution photographs than obtained with diver-collected cores. In addition, it finds objects (gas voids) that require expert judgment.

I provide a brief overview of using the diver wedge core in the field with a community group and obtaining quantitative results. The focus is on detection of the RPD as being the feature most related to aquaculture organic loading impact. A series of cores were obtained in a spatial grid in a bay including a single fallowed fish farming lease. Divers were instructed to minimize disturbance of the sediment surface during collection. In some cases, water overlying the core was present. On the boat deck, photographs were obtained with a consumer grade digital camera, adding an index card with station number, and taking care to avoid glare or shadows in the image (Fig. 1). Although it is possible to subsample the core for sediment aliquots after imaging, I conducted a separate collection process using a grab. Because I place an emphasis on spatial data, careful georeferencing is essential. As with digital cameras, many people are comfortable with handheld GPS, and most vessels contain more elaborate charting/GPS systems.

The primary focus in analyzing the images was the visual or aRPD, and the potential for citizens to participate in this stage. I first used Adobe Photoshop Elements to crop the image to contain only sediment, and to maximize contrast, which tends to enhance the difference between tan and black sediments. I then used freeware image analysis software ImageJ (http://rsbweb.nih.gov/ij/) to calibrate the image in real dimensions, and trace the line demarcating the RPD as well as the sediment surface. There is subjectivity associated with this step, and training is essential.

I attempt to capture variation in the aRPD in single cores compared to a horizontal line, providing an index of the irregularity of the aRPD trace. This is in addition to measuring the area of the aRPD and dividing by core width as a measure of average aRPD depth (Rosenberg et al. 2009). In the example provided $(<10 \mathrm{~m}$ water depth), the aRPD is clearly visible in the image, with potentially more than one aRPD stratum (Fig 2a). The vertical banding is typical of SPI images, and likely influenced by bioturbation. This is a sandy sediment, $<1 \mathrm{~km}$ from shore with abundant fauna (Aricidea catherinae, a small burrowing paraonid polychaete, at densities $>10^{3}$ ind. $\mathrm{m}^{-2}$ ), likely influenced by wave action near the coast. The cores do not always retain overlying water, especially in porous sand, and there is potential for disturbance of the sediment-water inter- 
face. In addition, because the surface is not entirely level, the foreground line (traced in Fig. 2a), can be obscured by background relief.

Image analysis of 2 redox-based variables indicates that the length of the aRPD line is $20.9 \mathrm{~cm}$, compared to a core width of $15 \mathrm{~cm}$, indicating that this line is 1.4 more anfractuous than a straight line. The average depth of the upper aRPD is $3.6 \mathrm{~cm}$, a substantial oxidized layer located $\sim 1.9 \mathrm{~km}$ from the culture site (Fig. 2a).

A core from beneath a site of recent salmon aquaculture shows the aRPD to be at the sediment surface (Fig. 2b). While there are no features to analyze in this image, it demonstrates that the end member (no oxidized layer) can be detected by this method. One might anticipate that these sediments would be depauperate or contain a classic opportunistic assemblage according to the Pearson-Rosenberg paradigm (Pearson \& Rosenberg 1978). It is notable that faunal samples from this site were indicative of moderate disturbance according to the M-AMBI faunal index of Borja et al. (2009b). This suggests some degree of recovery post-fallowing, despite the reduced condition of the sediment.

\section{DISSEMINATION OF RESULTS}

Provision of spatial data to non-specialists is an active research area, contained within the topic of PPGIS (Public Participation Geographic Information
Systems). It has been used in a variety of applications, including decision support for environmental management (Craig et al. 2002). When information is collected by citizen groups, 2 initial steps are necessary for its inclusion in the decision process: (1) The data must be archived, presumably by the regulators. Transfer of images by email or web sharing is easily achieved (Herath et al. 2005). Data in the form of images are readily managed, and many people are comfortable in dealing with files of JPG or other photographic formats. This step is also important in facilitating data sharing among stakeholders. (2) Data must be analyzed by designated individuals or groups according to the processing steps outlined above. Data validation through training of citizen analysts and subsequent quality control is paramount.

For presentation, mapping is the natural mode for spatial data. Other analyses such as geospatial modeling are more oriented toward specialists, compared to techniques such as plotting of data in space with graduated symbols. Mills \& Curtis (2008) review the implementation of geospatial tools by community groups in reference to topics such as disease outbreaks and natural disasters. Among these approaches, Google Earth may be considered an interactive GIS. Plotting of spatial data is facilitated by websites such as GPSVisualizer.com, which simplify addition of graduated symbols to Google Earth. The resulting KML files can easily be shared by email. The images themselves may also be geotagged for display on Google Earth.

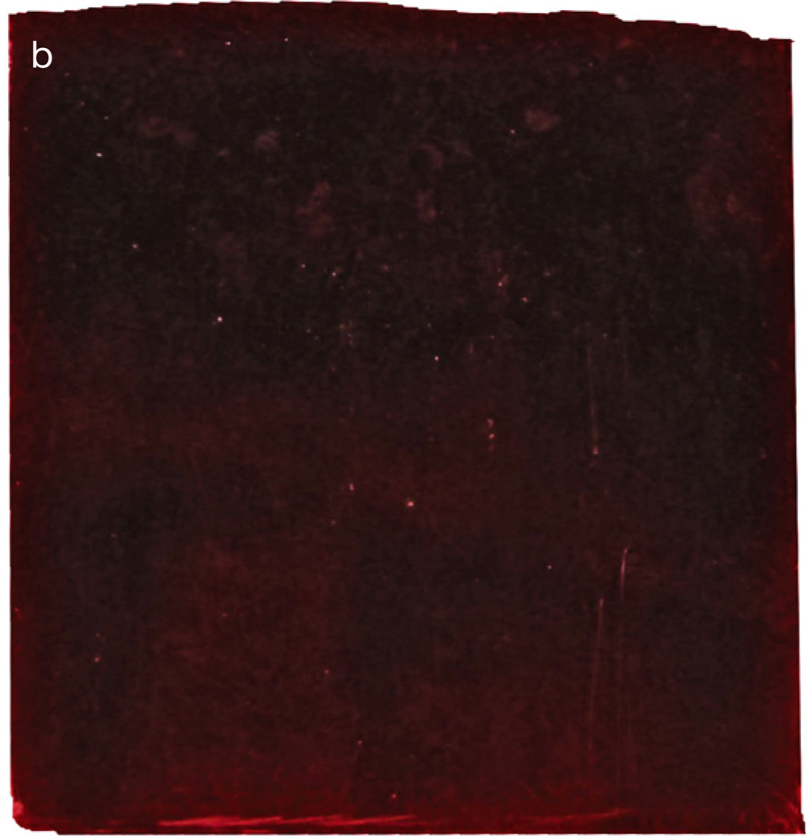

Fig. 2. Sediment profile images (false colour) from the Hargrave wedge core from (a) coastal Nova Scotia $(<10 \mathrm{~m}$ depth) with lines demarcating the sediment surface and depth of the apparent redox potential discontinuity (aRPD), and (b) directly below fallowed salmon cages; entire sediment column is reduced sediment, and the aRPD is at $0 \mathrm{~cm}$. Image width is $15 \mathrm{~cm}$ 
Other formats such as geoPDF (TerraGo Technologies, www.terragotech.com) are very effective at disseminating mapped results, since all the layers are contained within the familiar PDF format, without the complication of GIS software. In addition, unlike Google Earth, the results are less dependent on online access.

Although these geospatial tools provide a repository for environmental data, they do not exclude the addition of data layers selected by coastal residents, including traditional knowledge (Close \& Brent Hall 2006). For example, fishers have extensive knowledge of local bathymetry and bottom type which may be included as metadata, polygons, or sketches on Google Earth maps. The results of SPI image analysis, including the aRPD measurements discussed above can be plotted using these approaches. In the SPI literature, it is surprising how few examples exist of mapped results, either as graduated symbols or modeled contours.

\section{DISCUSSION}

Aquaculture must be considered within the context of coastal zone management. Ideally, a standard set of tools and approaches would deal with many types of coastal development. GIS, decision support, and mapping tools exist for this purpose, and their wider integration into coastal planning is needed. While the details of proposed development projects involve specific impacts, a common denominator of impact assessment is feasible. For example, aquaculture development might involve evaluation of eutrophication effects, while heavy industry might involve monitoring of various contaminants. Yet both assessments could be based on sedimentary parameters. Likewise, the provision of information to coastal residents would be similar at some levels, such as location maps for proposed activity, and the added data layers described previously.

\section{SPI interpretation and the far-field}

The application of science to community-based management has at least 2 important considerations: (1) is the proposed scientific technique validated for its intended purpose? (2) Is it appropriate for translation to community groups in terms of execution, analysis and interpretation? SPI fulfills both of these criteria; it is an integrated measure of ecosystem health combining habitat features, bioturbation, community structure, and sediment geochemistry. Specifically, habitat quality objectives involving oxic conditions are explicit. Because it is based on images rather than something more arcane to the public such as chemical species or taxonomy, it is appropriate for use by citizen scientists.
Moreover, the Hargrave corer version demonstrated herein and in previous studies (Wildish et al. 2003, Callier et al. 2008) contains sufficient information for evaluation of the aRPD. It is not without problems though. The interpretation of sedimentary features, such as the aRPD is subjective, so interaction with specialists is necessary. In addition, there is variation in image quality associated with positioning the core on the boat deck, and a simple frame holding both camera and core would improve this step. The commercial in situ SPI camera provides a more detailed image of the sediment column, and thus greater potential for resolving other features such as bioturbation. Despite the cost, an ability to share among multiple stakeholders makes the commercial version a worthwhile investment for government purchase and provision to coastal communities. There are new in situ SPI devices on the market at much lower cost that will make the higher quality images more available, and avoid the need for divers.

Nonetheless, the question of far-field impacts requires careful definition. First, the chosen methodology defines potential for detecting impacts. For example, the SPI technique is specific to organic loading from any source, and once beyond the limits of farm influence, variables such as RPD depth would be determined by natural variation in organic deposition, e.g. as a function of grain size. The appearance of high sulfides or shallow RPD at the sediment surface is less common under natural conditions, or occurs in specific locations such as the upper reaches of a poorly flushed tidal creek. Therefore, one might expect to see a gradient of oxidized conditions, with an increase in RPD depth away from farm sites. However, other anthropogenic impacts such as a fish plant or river mouth could contribute to organic input and thus eutrophication effects in the benthos, obscuring any gradient. In this case, the depth of RPD could not be used as a measure of far-field impact. However, in eastern Canada, coastal communities are often sparsely populated, and the presence of extraneous nutrient sources is infrequent. Under these conditions, SPI could be used to demonstrate the lack of far-field impacts away from seafarming operations. Other potential far-field impacts such as nuisance algae would require alternative methods of detection. Nonetheless, under either of these scenarios, a spatial survey of RPD using SPI provides a map of benthic conditions. Using contouring or other geostatistics, sedimentary variables at the farm and potentially the larger system (bay) are interpretable in a wider spatial context as in the delineation of 'hotspots'. Although one cannot ascertain a priori that culture impacts will be distinguishable as a spatial gradient, there is potential evidence in this approach as to whether they are limited to farm areas, or affecting the entire system. 


\section{Logistics}

This research program included more types of samples (fauna, sediment) than just SPI, and there is clearly an advantage in additional data layers. Other complementary types of imaging may also be beneficial, including sediment surface photography (Wilson et al. 2009), a technique I have employed at other aquaculture sites. The analysis of other variables may require specialists, dissociating from public participation except at the collection stage. I note that participatory science facilitates accomplishment of parallel specialist science. From a logistical perspective the participation of local residents, including vessel resources, is helpful to any of these efforts. However, the field work often has educational benefits for stakeholders associated with viewing sedimentary features in the field, in addition to the joint labor and sharing of boats/equipment. Universities make ideal partners in these efforts. In the present case, scientific divers (students and a divemaster) from the university conducted the SCUBA portion, although in other stages of the work, divers from the community participated. I have a funded research program on indicators of coastal ecosystem health, so dedication of resources to this work was not an issue. However, funds were also available from the community group to compensate divers, pay for sediment chemistry, etc. It is important to emphasize that there is no advocacy on my part in leading/joining this research; I simply hoped to bring more science to the table to assess effects of salmon farming in local waters. A representative from the salmon farm participated in the field work and provided full access to the lease sites. It may be difficult for government agencies to be science partners, since their activity with stakeholders may be viewed as 'taking sides'.

\section{SPI and sustainability}

Fraser et al. (2006) discuss the importance of 'bottom up' indicators of sustainability, e.g. those developed via community initiatives instead of through top down government directives. In the present case, there were definitive ideas within the community about types of impacts arising from fish culture, and an appreciation for the importance of measuring far-field impacts. Fishers and others with wide experience on the sea had solid notions of what might indicate ecosystem health, although their collaboration with scientists was essential in narrowing the focus to a quantifiable measurement. Methods such as SPI are not meant to be conducted in isolation or opposition to those enlisted by regulators. Although SPI has widespread use in many marine management decisions, it is less commonly used in Canada. Beyond its validity in the literature, demonstration of local success and efficiency of SPI may feedback to the monitoring protocols of regulators in a positive way.

Consequently, there is a win-win aspect to this approach. Coastal residents gain the ability to supervise some of the data collection and analysis which affect development in their community. This may reduce the suspicion with which relevant data are sometimes viewed. In addition, regulators gain the benefit of spatially explicit data, with capacity to examine far-field impacts, noting the cautions discussed above. This aligns with practice of ecosystem-based management instead of considering just local impacts. Delineation of the far-field has at least 2 requirements: (1) a variable with some relevance to system condition or health, and (2) the capacity to be surveyed and analyzed in a cost-effective time frame as well as mapped. There is no doubt that SPI fulfills these conditions, accounting for its successful deployment throughout Europe as well as in other parts of the world (Mulsow et al. 2006, Rosenberg et al. 2009). While there are other far-field effects that are also important (escapees), many are not easily investigated by citizen participants in the same way as SPI.

There is a growing trend of bringing geographic information to communities for use in development scenarios (Craig et al. 2002). Limitations on these data however, may create only a proxy for sustainability criteria (Kearney et al. 2007) compared to a case like the present one where we collect primary data, directly related to ecosystem health. Maps of far-field variables have the additional advantage that they can be incorporated into GIS and modeled (e.g. contoured) to indicate spatial trends. These maps are easily distributed and provide an 'ecosystem view' that is missing in most monitoring programs. Compared to other forms of data such as bivariate plots, maps have the advantage of being familiar to most people. In fact, coastal residents such as fishers are adept at viewing hydrographic charts, which form the basis for much of the data mapping. The layout and density of the original spatial grid design is critical in interpretation of the mapped results (Caeiro et al. 2003), so experimental design is important.

Much of the literature on community-based management deals with governance and coordination of stakeholders as well as branches of government (BastienDaigle \& Vanderlinden 2008, Wilson \& Wiber 2009). The present situation involved only a single community group which included retired scientists as members, and a single aquaculture company. Moreover, the bay of interest was relatively small. Coordination and communication were thus greatly simplified. 


\section{Citizen science and decision support}

There are many successful examples of the willingness of coastal residents to participate in data collection (Evans et al. 2000, Foster-Smith \& Evans 2003). Among the most exemplary is the Atlantic Coastal Action Program (ACAP). Set up as a series of community-based monitoring and management programs in eastern Canada, and sponsored by Environment Canada, research and governance activities include water quality, air quality and habitat restoration (Ellsworth et al. 1997). Ongoing for almost 20 years, ACAP has been wildly successful in providing community input to coastal management. Citizen input has had numerous tangible results including reopening of shellfish closures, and documentation of contaminant levels in coastal waters (McNeil et al. 2006). This success verifies not only the embrace of community-based science in the area of Canada considered in the present paper, but the potential for its success in general. In fact, the positive experience of ACAP has been transferred to multiple countries (McNeil et al. 2006). Having mentored some of the early ACAP efforts, I can attest to the enthusiasm with which the work was initiated. Although there is no specific program established for analogous community science in aquaculture, a similar framework would be appropriate for the context of using SPI and complementary methodologies.

There are several options for sustainability indicators of land-based resources, but those in the ocean are limited by accessibility and logistics (Shackeroff et al. 2009). SPI data or similar types of information are only a part of the solution to conflicts arising from development scenarios. The long history of SPI includes generation of categorical classification such as BHQ, which can be used to set thresholds for acceptability (Rosenberg et al. 2009). The validity of the Hargrave corer SPI is well documented (Wildish et al. 2003, Callier et al. 2008). This information may be used with other indicators or criteria into multicriteria decision making (Kiker et al. 2005). The stages in this process are set out in integrated ecosystem assessment (IEA) (Ruckelshaus et al. 2009), including the spatial information provided by mapping of results. The entire decision process is dependent on the type of aquaculture scenario - new sites, re-development, stocking density, expansion of cage areas, etc. In the present case, the condition of the bay following the removal of fish was the primary issue. Mapping of aRPD based on SPI was the concern of the present study, although ancillary data on sediments and fauna were collected.

Obviously, in larger systems with multiple stakeholders, the process is more complex. However, the implementation of rigorous science, with applicability to ecosystem health, and capacity for public participation is key in ecosystem-based management.
Acknowledgements. This work was funded by a Strategic Project Grant from the Natural Science and Engineering Research Council of Canada to J.G. Thanks to Ramon Filgueira and Lin Lu for help in the field, Michael Schwinghamer for image analysis, John Lindley and the Dalhousie divers, and the community residents of the study site.

\section{LITERATURE CITED}

Bastien-Daigle S, Vanderlinden JP (2008) Learning the ropes: lessons in integrated management of coastal resources in Canada's Maritime Provinces. Ocean Coast Manag 51: 96-125

Borja A, Bald J, Franco J, Larreta J, Muxika I (2009a) Using multiple ecosystem components, in assessing ecological status in Spanish (Basque Country) Atlantic marine waters. Mar Pollut Bull 59:54-64

Borja A, Muxika I, Rodríguez JG (2009b) Paradigmatic responses of marine benthic communities to different anthropogenic pressures, using M-AMBI, within the European Water Framework Directive. PSZNI: Mar Ecol 30:214-227

> Caeiro S, Painho M, Goovaerts P, Costa H (2003) Spatial sampling design for sediment quality assessment in estuaries. Environ Model Softw 18:853-859

Callier M, McKindsey C, Desrosiers G (2008) Evaluation of indicators used to detect mussel farm influence on the benthos: two case studies in the Magdalen Islands, Eastern Canada. Aquaculture 278:77-88

Carroll ML, Cochrane S, Fieler R, Velvin R, White P (2003) Organic enrichment of sediments from salmon farming in Norway: environmental factors, management practices, and monitoring techniques. Aquaculture 226:165-180

Cicchetti G, Latimer JS, Rego SA, Nelson WG (2006) Relationships between near-bottom dissolved oxygen and sediment profile camera measures. J Mar Syst 62:124-141

Close CH, Brent Hall G (2006) A GIS-based protocol for the collection and use of local knowledge in fisheries management planning. J Environ Manag 78:341-352

Craig WJ, Harris TM, Weiner D (2002) Community participation and geographic information systems. Taylor \& Francis, London

Diaz RJ, Trefry JH (2006) Comparison of sediment profile image data with profiles of oxygen and Eh from sediment cores. J Mar Syst 62:164-172

Ellsworth JP, Hildebrand LP, Glover EA (1997) Canada's Atlantic Coastal Action Program: a community-based approach to collective governance. Ocean Coast Manag 36: $121-142$

Evans SM, Birchenough AC, Fletcher H (2000) The value and validity of community-based research: TBT contamination of the North Sea. Mar Pollut Bull 40:220-225

Filgueira R, Grant J (2009) A box model for ecosystem-level management of mussel culture carrying capacity in a coastal bay. Ecosystems 12:1222-1233

Fletcher S (2007) Converting science to policy through stakeholder involvement: an analysis of the European Marine Strategy Directive. Mar Pollut Bull 54:1881-1886

> Foster-Smith J, Evans SM (2003) The value of marine ecological data collected by volunteers. Biol Conserv 113:199-213

> Fraser E, Dougill A, Mabee W, Reed M, McAlpine P (2006) Bottom up and top down: analysis of participatory processes for sustainability indicator identification as a pathway to community empowerment and sustainable environmental management. J Environ Manag 78:114-127

Grant J, Bacher C, Cranford PJ, Guyondet T, Carreau M (2008) A spatially explicit model of seston depletion in dense 
mussel culture. J Mar Syst 73:155-168

Hargrave BT (2005) Environmental effects of marine finfish aquaculture. Springer-Verlag, Berlin

Heaslip R (2008) Monitoring salmon aquaculture waste: the contribution of First Nations' rights, knowledge, and practices in British Columbia, Canada. Mar Policy 32:988-996

Herath S, Binh NH, Raghavan V, Hien HM, Hoa ND, Xuan NT (2005) Development of an email-based field data collection system for environmental assessment. In: Jansky L, Uitto JI (eds) Enhancing participation and governance in water resources management. UN University Press, Tokyo, p 120-131

Holmer M, Argyrou M, Dalsgaard T, Danovaro R (2008) Effects of fish farm waste on Posidonia oceanica meadows: synthesis and provision of monitoring and management tools. Mar Pollut Bull 56:1618-1629

Hovik S, Stokke KB (2007) Balancing aquaculture with other coastal interests: a study of regional planning as a tool for ICZM in Norway. Ocean Coast Manag 207:887-904

Jonsson B (1997) A review of ecological and behavioural interactions between cultured and wild Atlantic salmon. ICES J Mar Sci 54:1031-1039

Kaufman L, Karrer LB, Peterson CH (2009) Ecosystem-based management for the oceans. In: McLeod $\mathrm{K}$, Leslie $\mathrm{H}$ (eds) Island Press, Washington, DC

Kawabe M (2004) The evolution of citizen coastal conservation activities in Japan. Coast Manag 32:389-404

Kearney J, Berkes F, Charles A, Pinkerton E (2007) The role of participatory governance and community-based management in integrated coastal and ocean management in Canada. Coast Manag 35:79-104

Kiker GA, Bridges TS, Varghese A, Seager TP (2005) Application of multicriteria decision analysis in environmental decision making. Integr Environ Assess Manag 1:95-108

McNeil TC, Rousseau FR, Hildebrand LP (2006) Communitybased environmental management in Atlantic Canada: the impacts and spheres of influence of the Atlantic Coastal Action Program. Environ Monit Assess 113:367-383

Meffe GK, Nielsen LA, Knight RL, Schenborn DA (2002) Ecosystem management: adaptive community-based conservation. Island Press, Washington, DC

Mills JW, Curtis A (2008) Geospatial approaches for disease risk communication in marginalized communities. Prog Commun Health Partnerships 2.1:61-72

Mulsow S, Krieger Y, Kennedy R (2006) Sediment profile imaging (SPI) and micro-electrode technologies in impact assessment studies: example from two fjords in southern Chile used for fish farming. J Mar Syst 62:152-163

Nilsson HC, Rosenberg R (1997) Benthic habitat quality assessment of an oxygen stressed fjord by surface and sediment profile images. J Mar Syst 11:249-264

Pearson TH, Rosenberg R (1978) Macrobenthic succession in

Editorial responsibility: Pablo Sánchez Jerez,

Alicante, Spain relation to organic enrichment and pollution of the marine environment. Oceanogr Mar Biol Annu Rev 16:229-311

Rhoads DC, Germano JD (1982) Characterization of organismsediment relations using sediment profile imaging: an efficient method of remote ecological monitoring of the seafloor (Remots ${ }^{\mathrm{TM}}$ System). Mar Ecol Prog Ser 8: 115-128

Rhoads DC, McCall PL, Yingst JY (1978) Disturbance and production on the estuarine seafloor. Am Sci 66:577-586

Rosenberg R, Nilsson HC, Diaz RJ (2001) Response of benthic fauna and changing sediment redox profiles over a hypoxic gradient. Estuar Coast Shelf Sci 53:343-350

Rosenberg R, Magnusson M, Nilsson HC (2009) Temporal and spatial changes in marine benthic habitats in relation to the EU Water Framework Directive: the use of sediment profile imagery. Mar Pollut Bull 58:565-572

Ruckelshaus M, Essington T, Levin P (2009) Puget Sound, Washington, USA. In: McLeod $\mathrm{K}$, Leslie $\mathrm{H}$ (eds) Ecosystem-based management for the oceans. Island Press, Washington, DC

Shackeroff JM, Hazen EL, Crowder LB (2009) The oceans as peopled landscapes. In: McLeod K, Leslie H (eds) Ecosystem-based management for the oceans. Island Press, Washington, DC

Sutherland TF, Petersen S, Levings CD, Martin AJ (2007) Distinguishing between natural and aquaculture-derived sediment concentrations of heavy metals in the Broughton Archipelago, British Columbia. Mar Pollut Bull 54: 1451-1460

Valente RM, Rhoads DC, Germano JD, Cabelli VJ (1992) Mapping of benthic enrichment patterns in Narragansett Bay, Rhode Island. Estuaries 15:1-17

Whitmarsh D, Palmieri MG (2008) Aquaculture in the coastal zone: pressures, interactions and externalities. In: Holmer M, Black K, Duarte CM, Marbà N, Karakassis I (eds) Aquaculture in the ecosystem. Springer, New York, NY

Wildish DJ, Hargrave BT, Pohle G (2001) Cost-effective monitoring of organic enrichment resulting from salmon mariculture. ICES J Mar Sci 58:469-476

Wildish D, Hargrave B, MacLeod C (2003) Detection of organic enrichment near finfish net-pens by sediment profile imaging at SCUBA-accessible depths. J Exp Mar Biol Ecol 285/286:403-413

Wilson L, Wiber MG (2009) Community perspectives on integrated coastal management: voices from the Annapolis Basin area, Nova Scotia, Canada. Ocean Coast Manag 52: 559-567

> Wilson SJ, Fredette TJ, Germano JD, Blake JA, Neubert PL, Carey DA (2009) Plan-view photos, benthic grabs, and sediment-profile images: using complementary techniques to assess response to seafloor disturbance. Mar Pollut Bull 59:26-37

Submitted: Februry 17, 2010; Accepted: August 18, 2010 Proofs received from author(s): September 28, 2010 